Perkins, F. T. (1958). J. gen. Microbiol. 19, 540-541

\title{
A Ready Reckoner for the Calculation of Geometric Mean Antibody Titres
}

\author{
BY F. T. PERKINS \\ Biological Standards Control Laboratory, Medical Research Council Laboratories, \\ Hampstead, London N.W. 3
}

Antibody titrations involve the use of serum dilutions and almost invariably the geometric mean antibody titre calculated for a group of sera gives useful data. The calculation of such geometric mean titres can be both time consuming and tedious, but it can be greatly facilitated by the use of a 'ready reckoner'. Table 1 gives the logarithmic values to base 10 of the reciprocals of serum

Table 1. Logarithmic values of antibody titres and their multiples

\begin{tabular}{|c|c|c|c|c|c|c|c|c|c|c|}
\hline \multirow{2}{*}{$\begin{array}{c}\text { Antibody } \\
\text { titre }\end{array}$} & \multirow[b]{2}{*}{$\log _{10}$} & \multicolumn{9}{|c|}{ Multiples of $\log _{10}$} \\
\hline & & $x 2$ & $x 3$ & $x 4$ & $x 5$ & $x 6$ & $x 7$ & $x 8$ & $x 9$ & $x 10$ \\
\hline 2 & $0 \cdot 3010$ & $0 \cdot 6020$ & 0.9030 & $1 \cdot 2040$ & $1 \cdot 5050$ & $1 \cdot 8060$ & $2 \cdot 1070$ & $2 \cdot 4080$ & $2 \cdot 7090$ & $3 \cdot 0100$ \\
\hline 4 & 0.6021 & $1 \cdot 2042$ & $1 \cdot 8063$ & $2 \cdot 4084$ & $3 \cdot 0105$ & $3 \cdot 6126$ & $4 \cdot 2147$ & $4 \cdot 8168$ & $5 \cdot 4189$ & 6.0210 \\
\hline 6 & 0.7782 & 1.5564 & $2 \cdot 8346$ & $3 \cdot 1128$ & $3 \cdot 8910$ & $4 \cdot 6692$ & $5 \cdot 4474$ & $6 \cdot 2256$ & $7 \cdot 0038$ & $7 \cdot 7820$ \\
\hline 8 & 0.9031 & $1 \cdot 8062$ & 2.7093 & $3 \cdot 6124$ & 4.5155 & $5 \cdot 4186$ & $6 \cdot 3217$ & $7 \cdot 2248$ & $8 \cdot 1279$ & 9.0310 \\
\hline 12 & 1.0792 & $2 \cdot 1584$ & $3 \cdot 2376$ & $4 \cdot 3168$ & $5 \cdot 3960$ & 6.4752 & $7 \cdot 5544$ & $8 \cdot 6336$ & $9 \cdot 7128$ & $10 \cdot 7920$ \\
\hline 16 & $\mathbf{1} \cdot \mathbf{2 0 4 1}$ & $2 \cdot 4082$ & $3 \cdot 6123$ & 4.8164 & 6.0205 & $7 \cdot 2246$ & $8 \cdot 4287$ & $9 \cdot 6328$ & $10 \cdot 8369$ & $12 \cdot 0410$ \\
\hline 24 & 1.3802 & $2 \cdot 7604$ & $4 \cdot 1406$ & $5 \cdot 5208$ & 6.9011 & $8 \cdot 2812$ & $9 \cdot 6614$ & $11 \cdot 0416$ & $12 \cdot 4218$ & $13 \cdot 8020$ \\
\hline 32 & $1 \cdot 5051$ & $3 \cdot 0102$ & 4.5153 & 6.0204 & $7 \cdot 5255$ & 9.0306 & 10.5357 & $12 \cdot 0408$ & $13 \cdot 5459$ & $15 \cdot 0510$ \\
\hline 48 & 1.6812 & $\mathbf{3} \cdot \mathbf{3 6 2 4}$ & $5 \cdot 0436$ & $6 \cdot 7248$ & $8 \cdot 4060$ & $10 \cdot C$ & 11 & $13 \cdot 4496$ & 15 & 8120 \\
\hline 64 & $1 \cdot 8062$ & 3.6124 & $5 \cdot 4186$ & $7 \cdot 2248$ & $9 \cdot 0310$ & $10 \cdot 8372$ & $12 \cdot 6434$ & $14 \cdot 4496$ & $16 \cdot 2558$ & $18 \cdot 0620$ \\
\hline 96 & 1.9823 & $3 \cdot 9646$ & 5.9469 & $7 \cdot 9292$ & 9.9115 & $11 \cdot 8938$ & 13.8761 & $15 \cdot 8584$ & $17 \cdot 8407$ & $19 \cdot 8230$ \\
\hline 128 & $2 \cdot 1072$ & $4 \cdot 2144$ & $6 \cdot 3216$ & $8 \cdot 4288$ & $10 \cdot 5360$ & $12 \cdot 6432$ & $14 \cdot 7504$ & $16 \cdot 8576$ & 18.9648 & $21 \cdot 0720$ \\
\hline 192 & $\mathbf{2} \cdot \mathbf{2 8 3 3}$ & $4 \cdot 5666$ & $6 \cdot 8499$ & 9·1332 & $11 \cdot 4165$ & $13 \cdot 6998$ & 15.9831 & $18 \cdot 2664$ & $20 \cdot 5497$ & $22 \cdot 8330$ \\
\hline 256 & $2 \cdot 4082$ & $4 \cdot 8164$ & $7 \cdot 2246$ & $9 \cdot 6328$ & $12 \cdot 0410$ & $14 \cdot 4492$ & $16 \cdot 8574$ & $19 \cdot 2656$ & $21 \cdot 6738$ & 24.0820 \\
\hline 384 & $2 \cdot 5843$ & $5 \cdot 1686$ & $7 \cdot 7529$ & $10 \cdot 3372$ & $12 \cdot 9215$ & $15 \cdot 5058$ & $18 \cdot 0901$ & $20 \cdot 6744$ & $23 \cdot 2587$ & $25 \cdot 8430$ \\
\hline 512 & $2 \cdot 7093$ & $5 \cdot 4186$ & $8 \cdot 1279$ & $10 \cdot 8372$ & $13 \cdot 5465$ & $16 \cdot 2558$ & 18.9651 & $21 \cdot 6744$ & $24 \cdot 3837$ & $27 \cdot 0930$ \\
\hline 768 & $2 \cdot 8854$ & $5 \cdot 7708$ & $8 \cdot 6562$ & & & $17 \cdot$ & & $23 \cdot 0832$ & 25 & 540 \\
\hline 1024 & $3 \cdot 0103$ & 6.0206 & 9.0809 & $12 \cdot 0412$ & $15 \cdot 0515$ & $18 \cdot 0618$ & $21 \cdot 0721$ & $24 \cdot 0824$ & $27 \cdot 0927$ & $30 \cdot 1030$ \\
\hline 1536 & $3 \cdot 1864$ & $6 \cdot 3728$ & $9 \cdot 5592$ & $12 \cdot 7456$ & $15 \cdot 9320$ & $19 \cdot 1184$ & $22 \cdot 3048$ & $25 \cdot 4912$ & $28 \cdot 6776$ & $31 \cdot 8640$ \\
\hline 2048 & $3 \cdot 3113$ & $6 \cdot 6226$ & $9 \cdot 9339$ & $13 \cdot 2452$ & 16.5565 & $\mathbf{1 9} \cdot 8678$ & $23 \cdot 1791$ & $26 \cdot 4904$ & $29 \cdot 8017$ & $33 \cdot 1130$ \\
\hline 3072 & $3 \cdot 4874$ & 6.9748 & $10 \cdot 4622$ & 18 . & 17 & $20 \cdot 9$ & $24 \cdot 4118$ & $27 \cdot 8992$ & $31 \cdot 3866$ & 34 \\
\hline 4096 & $3 \cdot 6123$ & $7 \cdot 2246$ & $10 \cdot 8369$ & $14 \cdot 4492$ & 18.0615 & $21 \cdot 6738$ & $25 \cdot 2861$ & $28 \cdot 8984$ & $32 \cdot 5107$ & $36 \cdot 1230$ \\
\hline
\end{tabular}

dilutions, together with their multiples. Thus, if in a group of twenty sera, each of two have antibody titres of 8, 32, 128 and 512 and each of four have titres of 64,256 and 2048 , the geometric mean titre for the group may be calculated as shown on p. 541 . 
Rapid calculation of antibody titres

\begin{tabular}{|c|c|c|c|c|}
\hline & $\begin{array}{c}\text { No. of } \\
\text { sera }\end{array}$ & & $\begin{array}{c}\text { Antibody } \\
\text { titre }\end{array}$ & $\log _{10}$ \\
\hline & 2 & at & 8 & 1.8062 \\
\hline & 2 & at & 32 & 3.0102 \\
\hline & 4 & at & 64 & $7 \cdot 2248$ \\
\hline & 2 & at & 128 & 4.2144 \\
\hline & 4 & at & 256 & $9 \cdot 6328$ \\
\hline & 2 & at & 512 & $5 \cdot 4186$ \\
\hline & 4 & at & 2048 & $13 \cdot 2452$ \\
\hline Total & 20 & & - & $44 \cdot 5522$ \\
\hline & $\log _{10}$ & & \multicolumn{2}{|c|}{$=\frac{44 \cdot 5522}{20}=2 \cdot 227$} \\
\hline
\end{tabular}

(Received 4 June 1958) 